\title{
Kuhn and Philosophy of Science in the Twentieth Century
}

\author{
Alexander BIRD*
}

\section{Introduction}

Thomas Kuhn was undoubtedly the strongest influence on the philosophy of science in the last third of the twentieth century. Yet today, at the beginning of the twenty-first century it is unclear what his legacy really is. In the philosophy of science there is no characteristically Kuhnian school. This could be because we are all Kuhnians now. But it might also be because Kuhn's thought, although revolutionary in its time, has since been superseded. In a sense both may be true. We are all Copernicans-yet almost everything Copernicus believed we now disbelieve. In this paper I shall examine the development of Kuhn's thought in connection with changes in the philosophy of science during the second half of the twentieth century. Now that philosophy in general, philosophy of science in particular, is in a post-positivist era, we all share Kuhn's rejection of positivism. But we do not, for the most part, share Kuhn's belief in incommensurability, or his scepticism about truth and objective knowledge. Just as in Copernicus' case, Kuhn initiated a revolution that went far beyond what he himself envisaged or even properly understood.

\section{Philosophy of science in the second half of the twentieth century}

Philosophy of science in the second half of the twentieth century underwent a curious apostasy and apparent reconversion. In the decades following the Second World War philosophy of science was still dominated by logical empiricism. Logical positivism, the most influential version of logical empiricism, was waning, but even so some of its central problems remained the concern of philosophers of science. And because of the central place given by the positivists to science and scientific knowledge, the problems of the philosophy of science were much the same set of problems that were to be found in the central areas of philosophy in general. For example, the problem of induction was a central one for positivist philosophers of science and even for antipositivist empiricists, like Popper. Yet, clearly, the problem of induction is central to general epistemology, and it affects beliefs that do not strike one as specifically scientific in character. Similarly, the solutions

* Department of Philosophy, 9 Woodland Road, Bristol BS8 1TB, United Kingdom 9 January 2004 
proposed, whether Carnap's inductive logic or Popper's falsificationism, even though framed within the context of the philosophy of science, were significant for epistemology in general. Thus, somewhat later, Hempel's accounts of scientific explanation and confirmation could nonetheless be illustrated in terms that could be scarcely less scientific.

Similarly, the characteristic semantic theses of positivism were often framed in quasi-philosophy-of-science terms: the meaning of a sentence is its method of verification; theoretical claims are reducible via meaning postulates to truthfunctions of observational propositions, and so forth. For the positivists and the logical empiricists more generally there was no significant demarcation between scientific knowledge and most of the rest of a posteriori knowledge: the sentences "there is a computer in front of me" and "atoms consist of electrons, protons, and neutrons" presented for Schlick and Carnap the same kinds of problem both semantically and epistemologically. Hence the same positivist theses could be undermined from different directions at the same time, whether philosophy of language (from Wittgenstein's attack on a private language, and from the ordinary language philosophy that followed) or the philosophy of science (the rejection an observation-theory dichotomy). Even Quine, for all his rejection of so much of positivism, retained this empiricist thesis, that science and the rest of empirical knowledge are not distinct. Indeed he broadened the scope of the thesis by assimilating mathematics, logic, and philosophy to empirical knowledge. Quine's holism, that all belief faces the tribunal of experience together suggests that all propositions, and the problems they raise for philosophers, differ not in kind but in degree. Einstein's dictum that science is refined common sense is appropriate both to Quine's viewpoint and to the positivists, except that for the latter the reverse might be more apt: common sense is unrefined science.

In the 1960s the relationship between philosophy of science and 'core' philosophy, earlier so close-one of identity in the minds of some philosophers-changed radically, so much so that it looked as if the philosophy of science had become divorced from the rest of philosophy and had set up home with a non-philosophical discipline, the history of science. This 'historical turn' in the philosophy of science had Kuhn especially to thank, as well as, most notably, Feyerabend, and Lakatos. (Much of the latter's work may in any case be seen in terms of a response to Kuhn.) Philosophers of science were no longer concerned with questions like 'Can we ever know any scientific theory to be true' but instead with questions like 'Why do theories change?' While the former may clearly be linked to questions in general epistemology, the latter seems ambiguous between looking for some general philosophical theory of theory-change and a causal, historical account of theory-change. 
At the very least, any philosophical account of theory-change would need to be validated by reference to historical case studies. Lakatos took this approach. In Kuhn's hands the distinct roles of the history and philosophy of science are not clear. Is The Structure of Scientific Revolutions a work of history or of philosophy ? ${ }^{1}$ Kuhn's answer is that it is both: it is history written for philosophical purposes. ${ }^{2}$ This sort of interconnection between history of science and philosophy of science had the effect of promoting their combination as a new unified discipline-history and philosophy of science-even though Kuhn later rejected the idea that there is such a discipline. It also had the effect of making philosophy of science look very much less like core philosophy than it had done previously. The issues of theorychange just discussed do not look like the philosophical worries of epistemology that happily focus on the formation of everyday, unscientific beliefs. Kuhn and his contemporaries raised other problems that were original to the philosophy of science, such as the theory-dependence of observation and incommensurability.

A significant product of the historical philosophy of science, and strongly influenced by Kuhn and Feyerabend, was the development of more or less relativistic and constructivistic history and sociology of science. The central claim of this wing of science studies is the symmetry principle, which asserts that rationality and irrationality must be given equal treatment in the explanation of scientific change, as must truth and falsity. ${ }^{3}$ That being the case, traditional philosophical explanations of theory choice (that they are rational given the evidence) are excluded, and sociological explanations take precedence. In some cases the sociological determinants were taken to be factors existing outside science (such as political allegiance). Kuhn himself much later commented on this and rejected it. It may be said that not all sociologists of science, not even all those who adhere to the Strong Programme, think that the sociological factors in question are usually external to science, and many see themselves closer to Kuhn than he saw them to be. His explanation of normal (and, by extension, revolutionary) science in terms of an exemplary scientific achievement that becomes a standard via its role in scientific education is clearly a sociological explanation. Whatever the merits of the sociology of science, and whether or not the sociologists of science would be right to see themselves as heirs to Kuhn, the fact remains that the philosophical problems raised by those sociologists served further to distance philosophy of science from central

${ }_{1}$ T.S. Kuhn 1970a The Structure of Scientific Revolutions (2 ${ }^{\text {nd }}$ edition) Chicago: University of Chicago Press.

2 T.S. Kuhn 2000 "A Discussion with Thomas S. Kuhn in T.S. Kuhn 2000 The Road Science Structure Chicago: University of Chicago Press, 276.

${ }^{3}$ B. Barnes and D. Bloor 1982 "Relativism, Rationalism, and the Sociology of Knowledge" in M. Hollis and S. Lukes (eds.) Rationality and Relativism Oxford: Blackwell $1982 ; 21-47$. 
concerns in epistemology and metaphysics. There may (for some) be prima facie plausibility in the claim that belief in scientific theories has a sociological explanation and that the truth of those theories is in some sense socially constructed. But there is not even prima facie plausibility in the claim that my belief that there is milk in the fridge requires a sociological explanation or in the claim that the fact that there is milk in the fridge is socially constructed. In the Kuhnian era scientific belief and everyday belief raised quite different sorts of problem.

Matters do not look quite that way today. Without wishing to suggest that philosophy of science has returned to the central role it played for the positivists, it is nonetheless true that philosophy of science sees itself as drawing much more strongly on results in 'core' epistemology, metaphysics, and philosophy of language, than it did in what I called the Kuhnian era. One reason is that radical developments in those core fields showed how to dissolve or deflate some of Kuhnian philosophy of science's most distinctive problems. A key example is incommensurability. Much of Kuhn's later work was concerned with adjusting and improving his account of incommensurability. In the wake of The Structure of Scientific Revolutions incommensurability was seen as a key component in the argument that science does not aim at increasing verisimilitude or at the accumulation of knowledge. But now very few philosophers of science regard incommensurability as a significant phenomenon, even if when characterised in some sufficiently weak way (such as the impossibility of perfect translation) they are willing to accept that it might exist. Why the change in view ?

\section{Kuhn and contemporary philosophy of science}

Kuhn's relationship to recent philosophy of science is best illustrated by a discussion of his incommensurability thesis. Incommensurability is primarily a thesis about meaning. There is no common measure of theories, it claims, because the meanings of key theoretical terms are different when employed in theories attached to different paradigms. Although incommensurability does not mean non-comparability, it does rule out certain kinds of comparison-for example, the point by point comparison that Kuhn associates with Popper and with the (then) positivist orthodoxy. (It does not rule out, apparently, Kuhn's kind of theory comparison according to which theory A is better than theory B if A possesses B's problem solving powers and is able to solve some of B's anomalies. It is not entirely clear, given Kuhn's earlier views on incommensurability, how even this comparison is possible.) Incommensurability arises since Kuhn adopts a theoretical context account of meaning. The meaning of a theoretical term is identified with the role it plays within a theory. The whole theory or at least a large part of it is 
implicated in the meaning of the term. So when there is a change of theory there is a change of meaning, and incommensurability arises. As far as many philosophers of science are concerned the innovation that led to the downfall of incommensurability was the development of causal theories of reference. Following Kripke and Putnam especially, focus shifted away from meaning (understood as Frege's 'sense') and onto reference. ${ }^{4}$ Two theses in concert undermined the significance of incommensurability. First was the thesis that reference not meaning is what is at stake in theory comparison (thesis 1). Second was the thesis that reference is fixed not by theoretical context but by a causal link between the use of the term and the entity or kind of entity referred to (thesis 2). Thesis 1 means that there is no automatic inference from difference in meaning to non-comparability. Thesis 2 ensures that when theoretical context or meaning changes no change in reference need follow. Hence, although some conception of incommensurability as nontranslatability may remain that thesis now have much less philosophical significance than it previously did.

It should be pointed out that thesis 2 did not remain entirely intact. Various problems with the simple causal account of reference required bringing back something like the sense or meaning of a term as fixing its reference, where the sense is determined by some part of the theoretical context. The causal component was retained to the extent that the theoretical context in question would be that part of the theory which asserts, fairly generally, the causal or explanatory role of item being referred to ; for example, the sense of 'electron' might be 'electrons are those subatomic particles responsible for electrostatic phenomena'. The two important things to note are first that the quantity of theory employed in fixing the extension is small and its content is general not specific. The rest of the theory of electrons may change without changing this part of the theory. Hence there is no reason to suppose that a change in theory must lead to a change in sense. And if there is no change in sense there will be no change in reference either. Secondly, thesis 1 is still intact. Reference is what matters in theory comparison. So if reference does not change with theory change, there will be no problem raised for theory comparison by theory change.

These developments highlight two important features of the relationship

${ }^{4}$ See, for example, H. Putnam 1975 "The 'Meaning of 'Meaning"' in Putnam 1975 Mind, Language, and Reality: Philosophical Papers Vol. 2 Cambridge: Cambridge University Press, 215-71 ; S. Kripke 1971 "Identity and Necessity" in M. Munitz (ed.) 1971 Identity and individuation New York: New York University Press, 135-64 ; S. Kripke 1972 "Naming and Necessity" in D. Davidson and G. Harman (eds) 1972 Semantics of Natural Language Dordrecht: Reidel, 763-9. 
between Kuhnian thinking and contemporary philosophy of science. First, a distinctively Kuhnian thesis, one that marked philosophy of science out as having problems different from the rest of philosophy, was undermined by central developments in metaphysics and the philosophy of language.

Secondly, Kuhn's incommensurability thesis had two components (i) a conception of theoretical meaning as informed by the whole of its theoretical context, (ii) an emphasis on meaning over reference. These views he inherited from his positivist predecessors. The theoretical context account of meaning was developed by Carnap, Nagel, and others (in the form of the double-language model) as a response to their failure to provide a reductionist account of theoretical meaning (whereby all theoretical meaning was to be analysed in terms of observational expressions). Kuhn took this on board, adding the thesis of theory-dependence of observation. The latter addition meant that theory-comparison could not be achieved by the comparison of observational consequences of theories. Kuhn's disdain for reference is also inherited from the positivists. The positivists sought to avoid any commitment to theoretical entities-hence their original efforts to analyse all theoretical expressions in terms of observational ones. And so, even with later developments such as the double-language model and the theoretical context account of meaning, the positivists did not think that theoretical terms ever referred to anything. The issue of reference as the basis of theory comparison just never arose for them. Thus the resurgence of reference and the arrival of the causal theory and its successors represented a far more radical departure from positivism than anything Kuhn proposed-Kuhn's incommensurability thesis can be seen as positivism plus the theory-dependence of observation. ${ }^{5}$ From this angle, for all the apparently dramatic implications of incommensurability, it can be seen as decidedly conservative and old-fashioned in its commitments.

The same positivist legacy in Kuhn's thinking may be seen in his more general epistemological outlook. Here too, I claim, Kubn's version of relativism and scepticism, and his rejection of knowledge as the aim of science, show an adherence to empiricist and Cartesian thinking, even though he saw himself as reacting against these traditions. In this case, however, I think Kuhn came close to breaking the mould. In his earlier thinking, Kuhn shows a naturalism, a willingness to use the results of the empirical sciences, especially psychology, in framing his account of theory change. This, I believe, would have been truly radical had he followed it through. Unfortunately this naturalism makes little appearance in his later thinking. There he replaces naturalism with a priori thinking that leads him into a kind

${ }^{5}$ See W. Newton-Smith 1981 The Rationality of Science London: Routledge and Kegan Paul, 151-6, for a version of this view. 
of neo-Kantianism, which I shall discuss later.

It seems therefore that although Kuhn took himself to be rejecting positivism, he nonetheless rejected these developments in philosophy that from today's perspective look to be the most important breaks with positivism. Positivism was simultaneously optimistic about science, and anti-realist. It was optimistic in that it believed, as mentioned, that science is the best example of a posteriori knowledge, and that correspondingly science progresses by systematically adding to this knowledge and getting closer to the truth. It was anti-realist in that positivists did not accept that science revealed the existence and nature of unobservable entities. The rejection of the ability to know about the unobservable was not a limitation on science (and hence was not a failure of optimism about science). Rather it was held to be part of the rejection of metaphysics. Since the positivists rejected the unobservable, the idea of our scientific terms referring to unobservable entities was rejected also-or, rather, did not arise and so was scarcely even considered. My proposal is that Kuhn felt he was rejecting positivism when he rejected the positivists' simple optimism about science, but failed to appreciate that what was rather more characteristic of logical positivism was its anti-realist rejection of the unobservable and the corresponding notion of reference to the unobservable. The latter failure on Kuhn's part was itself probably due in large part to the fact that Kuhn lacked any extensive formal philosophical training. His understanding of philosophy and its history in the twentieth century was so thin that he simply didn't see this point. Instead, he saw that a realist approach to the unobservable and a causal theory of reference that allows us to refer to the unobservable permit a re-adoption of the optimistic aspect of positivism. To Kuhn therefore that looked like a return to something close to positivism. But in fact it was nothing of the sort. Optimism about scientific knowledge is much less a badge or mark of positivism than antirealism. And so even if it is true that the return to optimism shares something with positivism, that similarity is achieved by introducing a far more radical break with positivism, viz. referentialist semantics and the possibility of reference to unobservable entities.

The Structure of Scientific Revolutions was not a philosophical book in the normal sense, nowhere discussing the work of philosophers and rarely engaging directly with recognizable philosophical theses. I have described it as 'theoretical history of science' while Kuhn called it 'history for philosophical purposes'. Despite this fact it caused considerable interest among philosophers, particularly

${ }^{6}$ This colloquium lead to the volume I. Lakatos and A. Musgrave (eds) 1970 Criticism and the Growth of Knowledge Cambridge: Cambridge University Press, in which Kuhn's work was also discussed by Lakatos and Feyerabend. 
after the colloquium that took place at Bedford College, London in 1965 at which Kuhn's work was discussed by Popper, Watkins, Toulmin and others. ${ }^{6}$ The interest taken in Kuhn's work by professional philosophers greatly pleased him, and it is clear that Kuhn was keen to be accepted as a philosopher. My view is that Kuhn's work moved away from the naturalistic elements in The Structure of Scientific Revolutions and towards a more a priori and overtly philosophical approach partly in order to become more recognizably philosophical. In this he succeeded, in that at Princeton and MIT he was employed as a philosopher, whereas at Berkeley he had been regarded by the philosophers as primarily an historian. ${ }^{7}$ Therefore, on the one hand Kuhn's lack of a thorough understanding of philosophy meant that the thesis he came to regard as his distinctive contribution to philosophy of science, the incommensurability thesis, is much more positivist and thus less radical than the development of realism and referentialism he resisted. At the same time, his need to be accepted among philosophers meant that what would have been a truly innovative and radical contribution, a naturalistic approach to the philosophy of science that can be found in The Structure of Scientific Revolutions was progressively abandoned in favour of a more traditionally philosophical, a priori, approach -which occurred, ironically, just as philosophy of science was beginning to open itself up to naturalism. ${ }^{8}$ In the next section I shall examine some of these developments in more detail.

\section{The development of Kuhn's thinking}

In so far as we view it as a philosophical work, a distinctive and unusual feature of The Structure of Scientific Revolutions is the use of empirical data. Of course, much of this data is evidence from the history of science, which sparked a debate between Kuhn, Lakatos and others about the role of history of science in informing philosophy of science. At the same time Kuhn also drew upon empirical evidence of a different kind. This was primarily psychological. For example, he employs psychological evidence is his argument for the theory-dependence of observation, where he refers to gestalt psychology in support of his claim that our observations are dependent on what prior beliefs or expectations we may have. He also cites the work of his (then) Harvard colleagues Bruner and Postman whose experiments with

7 After not getting tenure at Harvard, Kuhn took up a position at Berkeley, which he left when he was not given promotion in philosophy. He then went to Princeton and subsequently to MIT.

${ }^{8}$ I examine Kuhn's move away from naturalism and his motivations for doing so in detail is A. Bird 2002 "Kuhn's Wrong Turning" Studies in History and Philosophy of Science 33, 443-463.

9 T.S. Kuhn 1962 The Structure of Scientific Revolutions Chicago: University of Chicago Press, 62-65 ; J. Bruner and L. Postman 1949 "On the Perception of Incon- 
anomalous playing cards showed that our perceptual responses depend on expectations built up by prior experience. ${ }^{9}$ Subjects found it more difficult to describe accurately the colour of unusual playing cards, where the colours of the suits had been changed, than to describe ordinary cards. Kuhn extended these idea to suggest that one's perceptual response might be influenced by the theory one holds (and not merely by past perceptual experience).

Kuhn also believed that the psychological evidence shed light on the larger question of the functioning of paradigms in scientific thought. The positivist view was that scientific thinking is matter of following rules of rationality. These might be conscious or unconscious. The task of the philosopher was to recover and formalise these rules. Frege had done this for deductive thinking and Carnap's inductive logic was an attempt to do something similar for inductive reasoning. Kuhn's most important innovation was the rejection of this idea. Science is not a matter of following the rules of reason but is instead a more intuitive (and learnable) activity, akin to learning to recognize a face or to play the piano. Kuhn maintained that scientific thinking is to be understood in terms of judgments of similarity to exemplary instances of scientific problem solving. The exemplars might be found in the texts of a great scientist (e.g. Newton's Principia or Ptolemy's Almagest) or in textbooks and scientific training more generally. A proposed solution to a new scientific puzzle is judged on the basis of perceived similarity to such exemplars. 'An exemplary scientific puzzle solution' is the central meaning of Kuhn's term 'paradigm'. As a result of a scientific revolution, the scientists' paradigms-as-exemplars change. Kuhn holds that as a consequence the scientists' world-view changes and he notoriously says that the experience of undergoing such a change is akin to that of a gestalt shift. Clearly it is something of a leap from the psychological experiments that supported gestalt psychology and from the Bruner and Postman playing cards to the more extensive claim that science functions by paradigms (exemplary puzzle solutions) enabling scientists to learn to 'see' puzzles and their solutions, rather than by the deployment of reason. It is for this latter reason that Kuhn was not sure whether these psychological results showed how the mind worked in general, both in perceptual cases and in scientific thinking, or whether they merely provided an analogy for the operation of paradigms. ${ }^{10}$ Intriguingly Kuhn also refers briefly to other research he was carrying out in order to support this approach. In the Postscript 1969 to the second edition of The Structure of Scientific Revolutions Kuhn remarks that he was experimenting with a computer programme designed to model the operations of intuition. There is a

gruity : A Paradigm." Joumal of Personality 18; 206-23.

${ }^{10}$ Kuhn 1962, 65. 
footnote referring his readers to his paper "Second Thoughts on Paradigms", which when published a few years later expanded a little on the use of computer models. ${ }^{11,12}$ It also provides an extended discussion of the use of exemplars in learning terminology related to perceptible kinds. This is a reflection of Kuhn's putting a more explicitly linguistic slant on his conception of incommensurability and the function of paradigms, to which I shall return shortly.

In The Structure of Scientific Revolutions the notion of incommensurability has a significant linguistic component. But it is also clear that the root of incommensurability is the claim that perception and observation are not theory-independent but are influenced by the paradigm in which one is operating. It is these facts about perceptual psychology that Kuhn thought of as undermining positivism (and indeed the Cartesian tradition in general). The lack of a common set of observations in turn means that even observational terms cannot be expected to mean the same when used in different paradigms, even if the same word is used. This is a major part of the explanation of the phenomenon that inspired Kuhn early on, that Aristotle's physics made no sense when it is interpreted in contemporary terms, whereas if understood in its own terms, it could be seen to be a plausible scientific position. At the same time, it is also clear that Kuhn did not, in the early sixties at least, think of this linguistic incommensurability as the complete explanation of this phenomenon. Making sense of Aristotle is not simply a matter of achieving a better understanding of what Aristotle meant. It is also a matter of seeing why it would be appropriate for Aristotle to make the concrete claims he does. And appreciating that requires understanding what one is committed to by adopting an Aristotelian paradigm. The paradigm does a lot more than fix meaning. It fixes the puzzles it is appropriate to tackle, it provides a heuristic for helping the scientist to solve those puzzles, and it sets the standards whereby attempted puzzle-solutions are judged. Kuhn encapsulates this idea by saying that the paradigm determines the world in which the scientist works. A corollary of this is that when the paradigm changes, the scientist's world changes also. Some critics (and some would-be supporters) took this to be a sign of an extreme form of social constructivism or idealism. Much later, as we shall see, Kuhn did give the worldchange thesis a quasi-idealist, neo-Kantian slant (while others interpreted it within the linguistic framework Kuhn sought to develop). ${ }^{13} \quad$ But in the 1960s, the world-

11 Kuhn 1970a, 192, footnote 12.

12 T.S. Kuhn 1974 "Second Thoughts on Paradigms" in F. Suppe 1974 The Structure of Scientific Theories Urbana: University of Illinois Press, 459-482.

13 For a development of Kuhn's taxonomic version of incommensurability, see I. Hacking 1993 "Working in a New World: The Taxonomic Solution in P. Horwich (ed.) 1993 World Changes. Thomas Kuhn and the Nature of Science Cambridge MA : MIT Press, 275-310. 
change thesis was neither idealist not (primarily) linguistic. Instead it was psychological. As I have discussed, the clearest focus of the thesis concerns the function of the paradigm in determining perception and observation, while Kuhn also hoped the idea could be extended to the other non-perceptual functions of paradigms mentioned above, such as spotting and assessing solutions to puzzles. A prevalent conception of the explanation of behaviour in terms of reasons says that all one needs to give such an explanation is to detail a person's beliefs, desires, aims, decisions, and so on, as they appear to that person. In this sense, the 'world' encapsulates what is required to give a satisfactory reason-giving explanation of a scientist's thinking. Even if there is an objective, paradigm-independent world, that is not directly relevant to explaining the behaviour of the scientist, since the world does not present itself to the scientist in that guise.

I have emphasized that in The Structure of Scientific Revolutions Kuhn's approach draws considerably on empirical evidence in the course of making philosophical points. This is consonant with my claim that this book is theoretical history and with Kuhn's own statement that it is history for philosophical purposes. ${ }^{14}$ What that book does is to paint a generalized picture of the way scientific change actually occurs. Furthermore it provides an explanation of this pattern of change, in terms of paradigms. Lastly-and by no means least, although this is less precisely set out-it uses the forgoing to challenge accepted philosophical conceptions of scientific change. In this context it is entirely appropriate that empirical data should come to the fore, since Kuhn's first task is to establish how and why scientific change does take place, and data that throws light on the decision making processes of scientists is relevant to that.

In the 1970s this empirical element is left behind. Instead the tone is much more philosophical, the argumentation is a priori, and the examples are not actual experiments but thought-experiments. Kuhn's later thinking on incommensurability centred on the conviction that it could be understood as a certain kind of untranslatability between the language of the new theory or paradigm and that of the old, or in some cases untranslatability between competing paradigms. Kuhn emphasized that despite what some critics had taken him to mean, he did not intend incommensurability to mean non-comparability nor even incommunicability. Proponents of different paradigms can communicate and in many respects their paradigms can be compared. However, incommensurability does have the consequence that communication will be imperfect and imprecise, just as it is not possible to translate the English 'carpet' exactly into French. Similarly, theory-comparison

${ }_{14}$ A. Bird 2000 Thomas Kuhn Chesham: Acumen, 8, 281. 
cannot be of the point-by-point kind that Popper and others had envisaged. The search for a conception of incommensurability that is anchored in the philosophy of language had begun in the 1960s. In "Reflections on My Critics" Kuhn noted the parallel with Quine's indeterminacy of translation thesis. ${ }^{15}$ The important lesson for Kuhn was that incommensurability involves different ways of dividing up the things that populate the world, even if he did not continue to subscribe to the Quinean parallel. Kuhn first developed a quasi-Wittgensteinian position that learning kind-terms with samples could permit different categorisations; this position later evolved into his taxonomic account of incommensurability. ${ }^{16}$ Kuhn held incommensurability to arise from differences of taxonomy that are themselves consequences of differences in lexical networks. A lexical network consists in the set of terms used for categorisation. The meanings of these terms, held Kuhn, are interrelated in such a way that one cannot be changed without changing all. Hence any difference between two scientific taxonomies means that no term of each will translate any term of the other. ${ }^{17}$

Kuhn also acknowledged a related Kantian interpretation of incommensurability. ${ }^{18}$ This interpretation involves a quasi-Kantian distinction between the world-in-itself and a phenomenal world. The former is independent of our thoughts, but is largely unknowable, whereas the latter is partly constituted by our minds and is knowable. The phenomenal world is partly constituted by our minds because our perception of similarities and differences among things is conditioned by our categorisation of things and that in turn is dependent upon our paradigms. Where Kuhn differs from Kant most notably is that because this perception and categorization are paradigm-dependent, they change as a consequence of scientific

15 T.S. Kuhn 1970b "Reflections on My Critics" in I. Lakatos and A. Musgrave (eds) 1970 Criticism and the Growth of Knowledge Cambridge: Cambridge University Press.

16 Kuhn 1974.

17 Kuhn introduces a 'no overlap principle' to prevent evasion of this problem by looking for some over-arching, finergrained taxonomy, that will encompass both the taxonomies in question. See Kuhn 1991 "The Road Since Structure" in A. Fine, M. Forbes, and L. Wessels (eds) 1991 PSA 1990. Proceedings of the 1990 Biennial Meeting of the Philosophy of Science Association East Lansing: Philosophy of Science Association, 2-13. This is discussed at length in H. Sankey 1998 "Taxonomic Incommensurability" International Studies in the Philosophy of Science 12, 7-16.

${ }_{18}$ I think that Kuhn was encouraged to think of his views in this way as a consequence of his discussions with Paul Hoyningen-Huene. See P. Hoyningen-Huene 1989 Die Wissenschaftsphilosophie Thomas S. Kuhns: Rekonstruktion und Grundlagenprobleme Braunschweig: Vieweg, translated as Hoyningen-Huene 1993 Reconstructing Scientific Revolutions: Thomas S. Kuhn's Philosophy of Science Chicago: University of Chicago Press. 
revolution, whereas for Kant the categories and forms of intuition are fixed. ${ }^{19}$

This brief history of the development of Kuhn's thinking on incommensurability shows that the latter started as a thesis prompted by Kuhn's own experience as an historian of science and which he hoped to illuminate and even explain by using the tools of empirical psychology. But at the end of this history, the incommensurability thesis has been shorn of it a posteriori character and now re-emerges as an a priori and much more recognisably philosophical thesis. We are now invited to understand incommensurability by seeing it in relation to the great philosopher Kant rather than the gestalt psychologist Kohler. Even the earlier emphasis on the lessons of the history of science has disappeared. Kuhn asserts, "Many of the most central conclusions we drew from the historical record can be derived instead from first principles." 20

Even though Kuhn's thinking became more overtly philosophical in character it nonetheless went against the current with respect to the development of the philosophy of science during the same period. While it is true that the psychological elements in The Structure of Scientific Revolutions brought a negative reaction from philosophical commentators at the time, since then philosophy of mind and philosophy of science have become naturalised in such a way that the very elements that Kuhn abandoned now seem entirely acceptable in a philosophical discussion. Kuhn's philosophy of science shifted its focus away from paradigms and onto incommensurability. Again philosophical currents have been in the opposite direction. With increasing interest in cognitive science and artificial intelligence, paradigm-like notions, such as case-based reasoning have become familiar to the relevant philosophers. As Kuhn developed the incommensurability thesis, it was a thesis about meaning where 'meaning' is understood as something like 'sense'. During the relevant period philosophy of language shifted its focus from sense to reference. As explained earlier, this move itself constitutes a very sharp break with the logical positivists who were concerned greatly with meaning but not at all with reference. In this context, Kuhn's emphasis on meaning, his repudiation of referentialism, and the incommensurability thesis itself, with its origins in the theoretical-context account of meaning of Nagel and others, all look much closer to positivism.

19 Kuhn 1991, 12; Kuhn 2000, 104.

${ }_{20}$ T.S. Kuhn 1992 "The Trouble with the Historical Philosophy of Science" Robert and Maurine Rothschild Distinguished Lecture 19 November 1991 An Occasional Publication of the Department of the History of Science Cambridge MA : Harvard University, 10. 


\section{Conclusion}

Kuhn is widely seen as a revolutionary in the philosophy of science, even though he was not, at the time of writing The Structure of Scientific Revolutions, an established philosopher of science. As Kuhn himself remarks, revolutionary scientists are often outsiders to the field to which they make their revolutionary contribution. For some time it looked as if Kuhn had instituted a new paradigm in the philosophy of science. It even had a new method-historical philosophy of science -as well as new problems, such as incommensurability.

But the philosophy of science does not look that way today. Self-avowed Kuhnians are more common in the sociology of science (and to a lesser extent, history of science) than in philosophy of science. And even those Kuhnians were repudiated by Kuhn himself. ${ }^{21}$ Partly because he was an outsider to philosophy he was unable to appreciate that philosophy of science had gone beyond Kuhn in distancing itself from positivism. And thus when he rejected aspects of contemporary philosophy of science-notably referentialism and a realist conception of truth - he was unintentionally aligning himself more closely to positivism than to its opponents.

Nonetheless, this is not to say that everything in Kuhn's work has been superseded by contemporary philosophy of science. On the contrary, precisely because philosophy of science has become more naturalised and more open to cognitive science and artificial intelligence, the time has come to reappraise those naturalistic elements of Kuhn's thought that he himself abandoned. In particular Kuhn's account of the function of paradigms-as-exemplars and the psychological nature of a scientific revolution and a psychological rather than linguistic notion of incommensurability are all ripe for development with the tools of cognitive science and allied disciplines that were unavailable to Kuhn at the time he wrote The Structure of Scientific Revolutions.

${ }^{21}$ Kuhn 1992, 3. 